\title{
Tema 6. El juego en el proceso de desarrollo del niño
}

\section{Presentación}

Hasta hace poco el juego era visto como una actividad aislada dentro del desarrollo psíquico del niño, incluso se le consideraba de manera peyorativa, como espacio para perder el tiempo, pero en la actualidad el juego recobró su función de medio básico para el fortalecimiento de las actitudes y habilidades sociales del niño, considerándosele incluso como soporte motivacional y cognitivo de los aprendizajes socioespaciales, lingüísticos y lógico-matemáticos.

\section{Propósito (objetivo)}

Invitar al docente escolar y al padre de familia a que vea en el concepto y en la práctica del juego un medio fundamental para superar el individualismo, ya que facilita una adecuada construcción de la cooperación y el contrato social como marco de bienestar común. 


\section{Conceptualización general}

Ernesto García Posada (1999), al analizar los aportes del pedagogo Édouard Claparède, hace una breve recopilación de definiciones sobre el juego, entre las cuales destaca el carácter de cada una de ellas. Así, encuentra que el juego es visto como medio de entretenimiento, mecanismo para emplear la energía física, rasgo atávico de la ley biogenética, ejercicio de preparación para la vida, estímulo para el desarrollo del sistema nervioso, y en otros casos, ejercicio de entrenamiento de habilidades sociales base de las competencias ciudadanas.

Pero además de estas definiciones, Pedro Fulleda, del Instituto de Recreación y Deportes de Cuba, precisa que "para el historiador holandés Johan Huizinga [...] lo más importante incluso no es reflexionar acerca 'del lugar que al juego corresponde entre las demás manifestaciones de la cultura, sino en qué grado la cultura misma ofrece un carácter de juego"” (Fulleda, 2000, p. 1).

Desde la perspectiva de la cultura como juego, Fulleda señala que no todo juego enseña a vivir en sociedad, y aclara que los

juguetes tecnológicos altamente sofisticados - y por tanto muy atractivos al afán indagador infantil— que estimulan en los niños y niñas la agresividad, el individualismo, la competencia irracional y violenta, el afán consumista, así como también el surgimiento de actitudes discriminatorias de tipo étnico, sexual o basadas en el poder adquisitivo familiar, atentan — con toda la fuerza destructiva de una bomba de tiempo destinada a estallar en la futura vida adulta de esos niños- contra los recursos de identidad, solidaridad y participación social, que garantizan el desarrollo cultural en virtud de las tradiciones y los principios más valiosos de cada comunidad. (Fulleda, 2000, p. 2) 
Ahora bien, para precisar una definición del juego que se pueda aplicar al contexto educativo retomaremos a continuación algunas de las características del mismo ${ }^{1}$ :

- El juego requiere de un orden, unas normas creadas por el jugador o los jugadores.

- Reproduce segmentos de la realidad desde construcciones imaginarias.

- Como construcción libre, promueve la espontaneidad, la afectividad y desvirtúa el aburrimiento.

- Puede ser individual o grupal.

Para los niños el juego es su lenguaje cotidiano, establece estados de ánimo positivos que se traducen en alegría y diversión y que de paso incentivan el potencial creativo y la ensoñación de cada uno. Su desarrollo va en detrimento del individualismo y de la competitividad obstinada, enseña a compartir y a lograr metas en conjunto, establece el espacio para el aprendizaje y para llegar a acuerdos que funcionan como normas comunes. Es la principal posibilidad real y técnica que tiene el niño para sobrepasar su egocentrismo inicial ${ }^{2}$.

Según Slaby, citado por Guillermo Gutiérrez (2000), el niño pasa, después de su estado egocéntrico, por diferentes etapas de juego, las cuales categoriza de la siguiente manera:

- Juego paralelo: los niños en un espacio conjunto juegan cada uno de forma independiente.

1 Descripción inspirada en el Programa no Escolarizado de Educación Inicial, del Ministerio de Educación del Perú y la Fundación Bernard van Leer (BVLF) de Holanda.

2 Es importante tener en cuenta que los juegos varían si se dan entre solo el género masculino o femenino, o si involucra a ambos géneros: igualmente los juegos cambian según la edad y siempre reflejan elementos de su vida interior, ya sean vivencias de su hogar, de la escuela, de la comunidad o del país. 
- Juego asociativo: los niños pueden tener un tema u objeto común pero es solo esto lo que los integra y no una conciencia grupal; por ejemplo, jugar con una pelota.

- Juego cooperativo: los niños aceptan las primeras condiciones de un juego grupal, buscan respetar el orden, los roles y crean nuevas condiciones que hacen más interesante el juego. "El espíritu verdaderamente cooperativo abarca aceptación mutua, apoyo, compartir y resolución constructiva de los problemas por todos, y excluye la hostilidad, el que los niños se hieran, se decepcionen y se rechacen" (Slaby, citado en Gutiérrez, 2000, p. 46).

El juego tiene entonces múltiples consecuencias en el desarrollo psíquico y en el aprendizaje del niño:

- Posibilita una relación de este con el espacio.

- Promueve el conocimiento entre pares, y de paso la interlocución con estos.

- Le enseña a compartir y a lograr metas en grupo.

- Le indica que existen espacios para el diálogo y la escucha.

- Comprende el significado de ayudar a los demás y de ser ayudado.

- Enseña a distribuir responsabilidades y tareas.

- Fortalece su capacidad para participar y pertenecer a grupos.

- Lo empodera a partir del afianzamiento de sus posturas y creencias, expresándolas de una manera asertiva.

- Lo convierte en guardián de la norma y de los derechos de todos los participantes.

- Genera motivación para nuevos aprendizajes.

- Aprende a enfrentar el estrés, la ansiedad y el fracaso, y comprende que se trata de emociones que puede manejar y superar. 


\section{Acercamiento personal (reflexión)}

- ¿En su infancia en qué juegos grupales participó? ¿Eran competitivos o cooperativos?

- ¿A qué juegan los niños hoy en la vida diaria, en sus espacios de descanso?

- Como pedagogo o padre de familia ¿considera que los juegos promueven las actividades individuales o las actividades cooperativas?

- ¿Cómo cree que se pueden transformar, por medio del juego, los hábitos individualistas en procesos de participación grupal y solidaria?

\section{Actividades sugeridas}

Búsquedas en Internet y bibliotecas

Búsquedas de casos en prensa
- Profundice los conceptos de juego egocéntrico, paralelo, asociativo y cooperativo.

- Busque al menos diez juegos de carácter cooperativo, escríbalos en cartulinas pequeñas e intercámbielas con sus compañeros. Hagan un fichero de juegos y clasifiquen su pertinencia según la edad en la que pueden participar los niños.

- ¿Conoce algún niño que solo juegue en medios virtuales, (computador, celular, tableta)? Haga una breve descripción de la personalidad del niño que solo juega en pantallas, sin hacer evidente de quién se trata,y la de un niño que interactúa y socializa con otros niños. 
Preguntas para debates grupales

- ¿Creen que hay juegos que no sirven para nada? Expliquen sus respuestas.

- ¿Qué efectos tiene en la personalidad la educación basada en sistemas educativos donde se estimula la competitividad y se ignora el juego cooperativo?

- ¿Qué papel puede desempeñar el juego en la enseñanza y adquisición de reglas en entornos sociales y en espacios públicos de la vida ciudadana?

\section{Bibliografía básica}

Baraldi, C. (1999). Jugar es cosa seria. Rosario: Homosapiens.

David, M. (1971). Teoría del juego. Madrid: Alianza Editorial.

Huizinga, J. (1972). Homo Ludens. Madrid: Alianza Editorial.

Jiménez, C. (1996). La lúdica como experiencia cultural. Bogotá: Magisterio.

Winnicott, D. (1982). Realidad y juego. Barcelona: Gedisa.

\section{Bibliografía complementaria}

Andrés, T. (1991). Juegos, juguetes y ludotecas: Aportaciones del Primer Seminario Estatal sobre Juegos, Juguetes y Ludotecas. Madrid: Pablo Montesino.

Bañeres, D. et al. (2008). El juego como estrategia didáctica. Barcelona: Graó.

Caillos, R. (1958). Teoría de los juegos. Barcelona: Seix Barral.

Díaz, J. (1997). El juego y el juguete en el desarrollo del niño. Ciudad de México: Trillas.

Fulleda, P. (2000). Necesidad por el desarrollo. Seminario Formación de Educadores para la Juventud del año 2000. Medellín: Yaripa, Ficemea y Unesco.

García, E. (1999). Édouard Claparède: Didáctica del juego y pedagogía científica. En Maestros pedagogos II: Un diálogo con el presente. Medellín: Corporación Regional de Medellín. 
Gutiérrez, G. (2000). Manual de prevención temprana de la violencia. Medellín: Programa de Convivencia Ciudadana y Secretaría de Educación.

Sánchez, R. y Valdivia, G. (1994). Socialización infantil mediante el juego en el sur andino. Lima: Fundación Bernard van Leer y Ministerio de Educación.

Thió de Pol, C., Fusté, S., Martín, L., Palou, S. y Masnou, F. (2007). Jugando para vivir, viviendo para jugar: El juego como motor de aprendizaje. En M. Antón, Planificar la etapa 0-6 (pp. 127-163). Barcelona: Graó.

Tirado, M. (1998). El juego y el arte de ser... humano. Medellín: Universidad de Antioquia.

Toro, V. (2013). El juego como herramienta educativa del educador social en actividades de animación sociocultural y de ocio y tiempo libre con niños con discapacidad. Revista de educación social, 16, 1-13. 


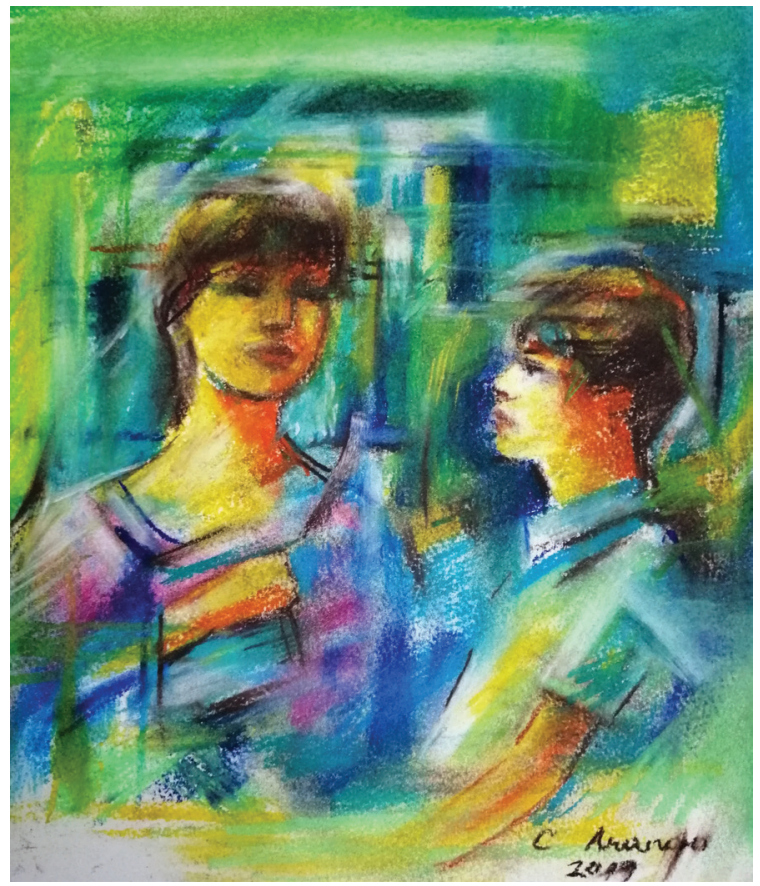

Inscribimos a la niña en este jardín infantil porque mi esposa también necesitaba trabajar, o sea, para ir a trabajar necesitaba a alguien con quien dejar a la niña y ella no se le puede confiar a cualquier persona.

Padre de familia

Hogar Infantil Fundehi, barrio El Arroyo, Cazucá, Soacha, 2017 